\title{
Seminario « Identidades, movilizaciones sociales y política(s) en América Latina»
}

Bogotá, 6-8 de noviembre de 2007

\section{Virginie Laurent}

\section{OpenEdition}

\section{Journals}

Edición electrónica

URL: http://journals.openedition.org/bifea/3770

DOI: 10.4000/bifea.3770

ISSN: 2076-5827

\section{Editor}

Institut Français d'Études Andines

\section{Edición impresa}

Fecha de publicación: 1 diciembre 2007

Paginación: 467-470

ISSN: 0303-7495

\section{Referencia electrónica}

Virginie Laurent, "Seminario «Identidades, movilizaciones sociales y política(s) en América Latina» », Bulletin de l'Institut français d'études andines [En línea], 36 (3) | 2007, Publicado el 01 junio 2008, consultado el 14 diciembre 2020. URL : http://journals.openedition.org/bifea/3770 ; DOI : https:// doi.org/10.4000/bifea.3770

Les contenus du Bulletin de l'Institut français d'études andines sont mis à disposition selon les termes de la licence Creative Commons Attribution - Pas d'Utilisation Commerciale - Pas de Modification 4.0 International. 


\section{SEMINARIO «IDENTIDADES, MOVILIZACIONES SOCIALES Y POLÍTICA(S) EN AMÉRICA LATINA»}

Bogotá, 6-8 de noviembre de 2007

Los días 6, 7 y 8 de noviembre de 2007 tuvo lugar en Bogotá un seminario internacional sobre «Identidades, movilizaciones sociales y política(s) en América Latina», organizado conjuntamente por el Instituto Francés de Estudios Andinos (IFEA) y la Facultad de Ciencias Sociales de la Universidad de los Andes, con el respaldo de la Embajada de Francia en Colombia, la Cooperación Regional Francesa para los Países Andinos y el Centro de Estudios Mexicanos y Centroamericanos (CEMCA).

Desde hace varios años el Instituto Francés de Estudios Andinos (IFEA) viene impulsando una reflexión sobre la movilización político-electoral indígena en los Andes y ha organizado dos seminarios internacionales sobre este tema: «Participación política, democracia y movimientos indígenas en los Andes» (IFEA, Programa de Investigación Estratégica en 
Bolivia-PIEB, Embajada de Francia en Bolivia) en La Paz, los 1 y 2 de diciembre de 2003, «Participación política indígena: integración e innovación política en los Andes» (IFEA, Centro de Estudios sobre los Movimientos Sociales del Ecuador-Cedime), en Quito, el 24 y 25 de noviembre de 2005. Con este tercer encuentro en Colombia, y de común acuerdo con la Facultad de Ciencias Sociales de la Universidad de los Andes, se buscaba abrir camino, desde un interés específico por las poblaciones indígenas hacia consideraciones más amplias acerca de las identidades (étnicas, raciales y culturales, o construidas alrededor de otros tipos de categorías y perspectivas, como - entre otras - el género o las movilidades). Así mismo, más allá de la participación electoral, quisimos interesarnos en las variadas formas de movilización social y política que surgen a partir de procesos de reivindicación identitaria e indagar en paralelo sobre la incidencia del argumento identitario en las políticas públicas. Por último quisimos abrir el foco de nuestras miradas, de la región andina hacia Latinoamérica, incluyendo casos de estudios mexicanos y centroamericanos además de los que tratan de Bolivia, Colombia, Ecuador y Perú.

Paralelamente el seminario apuntaba a propiciar un diálogo entre investigadores de múltiples disciplinas de las ciencias sociales y humanas (antropología, ciencia política, filosofía, historia, geografía y sociología) y representantes de organizaciones sociales, para favorecer exploraciones cruzadas sobre la manera cómo, en las últimas décadas, Latinoamérica ha estado marcada por dos procesos relativamente simultáneos: por un lado, la afirmación y politización de los particularismos, asociadas a la reivindicación del derecho a las diferencias; por otro lado, una apertura de los estados al multiculturalismo y a los discursos de género, marcando así una ruptura con un esquema de ciudadanía que anteriormente prohibía la expresión de las diferencias en la esfera pública. Tras las luchas indígenas y feministas de los años setenta y ochenta, América Latina se ha caracterizado en la década del noventa por el reconocimiento constitucional del carácter plural de la sociedad en numerosos países de la región y por la implementación de políticas de acción positiva destinadas a expresar una voluntad de respeto de las alteridades antes excluidas del ámbito político formal. Sin duda, las poblaciones indígenas son hoy en día las primeras en verse afectadas por tales medidas, siendo objeto de reconocimiento de una serie de derechos, unas veces generales en cuanto ciudadanos iguales que cualquier otro, otras veces particulares en su calidad de portadores de una identidad reivindicada como distintiva. Estos últimos comprenden el acceso a una educación, un sistema de salud, territorios, autoridades, una justicia y/o una representación política propios. No obstante, aunque sea en menor proporción y desde el ángulo discutible del «modelo» indígena, la validación oficial de las especificidades igualmente se ha extendido a otros grupos étnicos, como afrolatinoamericanos, al igual que rom y raizales en el caso colombiano. En el continente además, las mujeres han logrado cuotas de representación en listas electorales o cargos de designación. Así mismo, en años recientes, la diversidad sexual se impone como motivo de reconocimiento y objeto de debate público. Frente a tales cambios nos pareció entonces estimulante interrogar las interrelaciones posibles que se tejen entre las identidades, las movilizaciones sociales, la política - y las - políticas públicas en América Latina, para responder — entre otras - a las siguientes preguntas: ¿Cómo las identidades se conciben y se perciben, se invocan o se niegan? ¿De qué manera, por qué y para qué el argumento identitario llega — O no- a dar forma a movilizaciones sociales y propuestas políticas? ¿Con qué incidencia y para cuál proyecto de sociedad?

Para abordar estos interrogantes, el seminario se articuló en base a paneles de ponencias y debates, alrededor de tres ejes principales. En un primero, consagrado a las Identidades en - ¿o sin? - movimientos (6 de noviembre 2007), se buscaba reflexionar sobre el carácter móvil de las expresiones identitarias y su ubicación como objeto y argumento de acciones 
colectivas («invención de la tradición», «comunidades imaginadas»). Durante esta jornada se otorgó especial atención al impacto sobre las identidades de los movimientos tanto físicos como simbólicos. El segundo eje, Alteridades, desarrollo y gobernabilidad (6 de noviembre 2007), propuso explorar la relación entre alteridades, desarrollo y gobernabilidad teniendo en cuenta los procesos de construcción nacional y el papel del Estado desde una mirada que permita analizar el paso de ciudadanías fundadas en el universalismo a ciudadanías multiculturales. En el centro de los análisis se ubicaron las discusiones que surgen alrededor del acceso a recursos políticos, económicos y sociales, entre otros, así como alrededor de las normas y reglas que desde gobiernos nacionales y subnacionales rigen a la sociedad en su conjunto y/o conceden atribuciones específicas a ciertas categorías de la población. Finalmente, en el eje titulado Diferencias y dinámicas políticas: ¿acción contestataria, resistencias, participación electoral?, se examinó la manera cómo las diferencias alimentan dinámicas políticas impulsadas por los encuentros y desencuentros entre movimientos sociales, ciudadanía en general, partidos políticos y políticas públicas. En particular se propuso analizar formas de representación y participación política no sólo desde el ángulo de las reglas electorales y los partidos políticos sino también desde otras articulaciones forjadas entre sociedad y Estado (debate público, «resistencias cívicas», acciones contestatarias, entre otras).

Los tres días motivaron la presencia de veintidós panelistas, procedentes de universidades y centros de investigación de Latinoamérica y Francia: Juan Angola (Programa de Investigación Estratégica en Bolivia-PIEB), Carlos Agudelo (Centro de Estudios Mexicanos y Centroamericanos-CEMCA, sede Guatemala), Ingrid Bolívar (Departamento de Ciencia Política, Facultad de Ciencias Sociales, Universidad de los Andes), Margarita Chaves (Instituto Colombiano de Antropología e Historia-ICANH), Hervé Do Alto (Instituto de Estudios Políticos de Aix-en-Provence), Juan Guillermo Ferro (Facultad de Estudios Ambientales y Rurales, Pontificia Universidad Javeriana), Andrés Hernández (Centro de Investigaciones de Desarrollo Regional-CIDER, Universidad de los Andes), Virginie Laurent (Instituto Francés de Estudios Andinos-IFEA, sede Colombia), Julie Massal (Instituto de Estudios Políticos y Relaciones Internacionales-IEPRI, Universidad Nacional de Colombia), Adriana Maya (Departamento de Historia, Facultad de Ciencias Sociales, Universidad de los Andes), Donny Meertens (Escuela de Género, Facultad de Ciencias Humanas, Universidad Nacional de Colombia), Diana Miloslavich (Centro de la Mujer Peruana Flora Tristán), Cristina Oehmichen (Instituto de Investigaciones Antropológicas-IAA, Universidad Autónoma de México), Javier Ortiz (Departamento de Historia, Facultad de Ciencias Sociales, Universidad de los Andes e Instituto Francés de Estudios Andinos-IFEA, sede Colombia), Pablo Ospina (Área de Historia, Universidad Andina Simón Bolívar-UASB, sede Ecuador), Mercedes Prieto (Estudios de Género, Facultad Latinoamericana de Ciencias Sociales-FLACSO, sede Ecuador), Esteban Ticona (Carrera de Antropología, Universidad de San Andrés, La Paz), Marcela Velasco (Departamento de Ciencia Política, Facultad de Ciencias Sociales, Universidad de los Andes), Marcel Velásquez (Facultad de Letras y Ciencias Humanas, Universidad Nacional Mayor de San Marcos, Lima), María Emma Wills (Departamento de Ciencia Política, Facultad de Ciencias Sociales, Universidad de los Andes), Marta Zambrano (Departamento de Antropología, Facultad de Ciencias Humanas, Universidad Nacional de Colombia), Sergio de Zubiría (Departamento de Filosofía, Facultad de Ciencias Sociales, Universidad de los Andes). Así mismo, el seminario contó con un público amplio (cerca de 300 personas en total) compuesto por académicos, estudiantes y actores sociales, que participaron activamente en los espacios abiertos para la discusión.

Ante la variedad tanto del perfil de los asistentes como de los enfoques disciplinarios y de análisis durante el seminario, vale la pena destacar algunas reflexiones centrales que 
surgieron a raíz del encuentro. Por un lado, la aceptación consensual del carácter múltiple y fluctuante de las adscripciones identitarias, sin desconocer por otro lado, el cuestionamiento entre alguna/os de los participantes a la construcción y validez de categorías conceptuales tales como las de alteridad, etnicidad, subalternidad — haciendo implícitamente referencia a norma(s) impuesta(s) frente a la(s) cual(es) se es diferente- - Así mismo, si bien se reconoció lo pertinente de tener en cuenta la perspectiva de cruzar las identidades en los estudios, igualmente se hizo énfasis en lo difícil que resulta concretar semejante meta; al fin y al cabo, muchas de las investigaciones quedarían «encerradas» por privilegiar la remisión a unas pertenencias dadas (como indígena o «afro», como mujer o como desplazado) sobre otras posibles. De manera reiterada a través de las intervenciones tanto de los ponentes como del público, se examinaron además cuestiones enfocadas en la (des)territorialización de las identidades; en las interacciones entre lo global, lo regional y lo local; en la relación entre (des)igualdad(es) políticas, económicas y sociales, diferencia(s) y (re)distribución; o en la forma de combinar intereses y posiciones expresados a título individual o colectivo, tanto entre grupos sociales como desde el Estado y sus instituciones.

Por otra parte, se llamó frecuentemente la atención sobre puntos de encuentro y desencuentro entre los procesos de reivindicación identitaria a favor de una mayor representación y participación de grupos discriminados dentro de la sociedad y la implementación a partir de la década de 1990, de políticas públicas que apuntan oficialmente a la descentralización y la ampliación democrática, así como al multiculturalismo y la paridad entre géneros. Por cierto no se niegan avances significativos, en términos de reconocimiento de derechos o de la conquista de espacios y márgenes de negociación sin precedentes, como formas de empoderamiento para poblaciones anteriormente excluidas por completo de la toma de decisión. No obstante, transcurrida una década —o década y media - desde la adopción de los nuevos marcos normativos, los balances a establecer llaman a la prudencia: en primer lugar porque con la autonomía o emancipación relativa adquirida por grupos aglutinados alrededor de procesos identitarios - por ejemplo en cuanto a derechos territoriales o participación electoral-, pueden surgir nuevas dependencias — por ejemplo frente a políticas fijas de cuotas o en cuanto a la posibilidad de tener acceso a recursos económicos-; también porque la puesta en marcha de políticas fundadas en la acción positiva puede tener efectos perversos, tendiendo a homogeneizar — iesencializar? - los colectivos y corriendo el riesgo de generar discriminación intra e intergrupal, llevando a nuevos mecanismos de control social para impedir la acción contestataria o limitándose a cambios solo de fachada pero no en profundidad de las relaciones de poder en la sociedad. Múltiples incertidumbres que remiten a debates más amplios $-y$ sin respuesta definitivasobre cómo lograr proyectos de construcción nacional y ampliación democrática que signifiquen para toda/os inclusión, igualdad y equidad, sin someterse a las trampas paralelas de nuevos procesos de exclusión o absorción.

Virginie LAURENT 